\title{
DST and response to serotonergic antidepressants in obsessive - compulsive disorder
}

Dear sir,

Several groups have evaluated the response on the dexamethasone suppression test (DST) in patients with obsessive-compulsive disorder (OCD), reporting an incidence of abnormal tests ranging from $0-47 \%$ (Insel et al, 1982; Cottreaux et al, 1984; Lieberman et al, 1985; Monterio et al, 1986). To our knowledge, however, no study has so far been conducted to investigate the usefulness of DST in predicting response to pharmacotherapy in OCD patients.

In a previous paper, we reported that 5 out of 18 patients $(27.7 \%)$ meeting the DSM III-R criteria for primary OCD showed an abnormal escape from DST based on levels of plasma cortisol $>50 \mathrm{ng} / \mathrm{dl}$ at $4 \mathrm{pm}$, and that non-suppression was not related to the presence of depression (Catapano et al, 1990). Here we present some data concerning the relationship between DST response and outcome of treatment with 2 seroternergic antidepressants in 17 of these patients (11 men and 6 women; age range: $18-49$ years).

The patients, after baseline clinical assessment by the Yale-Brown Obsessive-Compulsive Scale (YBOCS) (Goodman et al, 1989), the Obsessive Compulsive Subscale of the Comprehensive Psychopathological Rating Scale (CPRS-OC) (Thorén et al, 1980), the 17-item Hamilton Rating Scale for Depression (HRSD) (Hamilton, 1960), and baseline biological evaluation (including the DST), were ran- domly assigned to either of 2 treatment regimens : fluoxetine (40 mg/day, in 2 oral administrations), or clomipramine $(150 \mathrm{mg} /$ day, in 3 oral administrations). Lorazepam (1-3 $\mathrm{mg} /$ day) was permitted to relieve insomnia. At the end of a 3-month treatment period, clinical status was assessed again by Y-BOCS. A score of 5 ('much improved') or greater on the item 18 (Global Improvement) of the YBOCS was required to define a patient as a 'responder' to treatment. Clinical evaluation was made by a psychiatrist who was blind to DST results.

Four out of 9 patients treated with fluoxetine and 3 out of 8 patients treated with clomipramine were classified as 'responders'. The 5 patients who were non-suppressors on DST at baseline were all nonresponders to treatment, whereas of the 13 suppressors 7 were responders and 6 non-responders (significant difference in the response rate between suppressors and non-suppressors, $P<0.04$, Fisher's exact test).

These data suggest that DST non-suppression may be a predictor of a poor response to serotonergic antidepressants in OCD patients.

\footnotetext{
Francesco Catapano, Palmiero Monteleone, Mario Maj, Dargut Kemali, Naples, Italy.
} 


\section{References}

Catapano F, Monteleone P, Maj M, Kemali D (1990) Dexamethasone suppression test in patients with primary Obsessive-Compulsive Disorder and in healthy controls. Neuropsychobiology 23, 53-56

Cottreaux JA, Bouvard M, Claustrat B, Juenet C (1984) Abnormal dexamethasone suppression test in primary Obsessive-Compulsive patients : a confirmatory report. Psychiatr Res 13, 157-165

Goodman WK, Price LH, Rasmussen SA, Mazure C, Fleischmann RL, Hill CL, Heninger GR, Charney DS (1989) The Yale-Brown Obsessive - Compulsive Scale. I: Development, use, and reliability. Arch Gen Psychiatry 46, 1006-1011

Hamilton M (1960) A rating scale for depression. J Neurol Neurosurg Psychiatry 23, 53-62
Insel TR, Kalin NH, Guttmacher LB, Cohen RM, Murphy DL (1982) The dexamethasone suppression test in patients with primary Obsessive - Compulsive Disorder. Psychiatry Res 6, 153-160

Lieberman JA, Kane JM, Sarantokos S, Cole K, Howard A, Borenstein M, Novacenko H, Puig-Antich J (1985) Dexamethasone suppression test in patients with Obsessive-Compulsive Disorder. Am J Psychiatry 142, $747-751$

Monterio W, Marks IM, Noshirvani H, Checkley S (1986) Normal dexamethasone suppression test in Obsessive-Compulsive Disorder. Br J Psychiatry 148, $326-329$

Thorén P, Asberg M, Cronholm B, Jorneotedt L, Traskman L (1980) Clomipramine treatment of ObsessiveCompulsive Disorder. I: A controlled clinical trial. Arch Gen Psychiatry 37, 1281-1285 